\title{
Imaging of the spinal cord
}

\author{
John M Stevens
}

\section{Methods of investigation \\ HISTORICAL PERSPECTIVE Air myelography}

The first contrast medium used to show the spinal cord was air. The first reports of its use to localise intraspinal tumours came from Jacobeus in 1921 and Dandy in 1925. ${ }^{1}$ The technique was later refined to show the entire spinal canal; this involved complete replacement of the CSF by air and distension of the spinal subarachnoid space. ${ }^{2}$ Adequate visualisation of the spinal cord usually required tomography. Spinal roots were not shown, and many types of pathology such as vascular malformations or arachnoiditis were either not shown or easily misinterpreted. Despite the fact that the technique was difficult to achieve and very hard on the patient, it remained the preferred method for visualising the spinal cord in many centres until the advent of non-toxic water soluble contrast only just over 10 years ago.

\section{Oil myelography}

At the time air myelography was being developed, it was found accidentally that iodised oils could be moved through the spinal subarachnoid space under the influence of gravity. They proved easier to use than air, and this quickly established oil myelography as the technique of choice especially in the lumbar spinal canal. It received even greater impetus from the appearances in 1940, of iophendylate (Myodil; Pantopaque), a preparation that was less viscous than the earlier Lipiodol and better for demonstrating the spinal cord. Myodil was very opaque to $x$ rays and special techniques such as tomography were not required. It was very slowly absorbed and could be left in the canal and rerun postoperatively to check the adequacy of decompression. Its main disadvantage was immiscibility with CSF; it tended to break up into globules, forming a layer in the spinal canal, which made it difficult to demonstrate both anterior and posterior surfaces of the spinal cord unless large amounts were used. For nearly 40 years, Myodil was generally the agent of choice, with air being reserved for special situations, such as spinal dysraphism and syringomyelia. As late as 1989 , eminent names in spinal surgery were still declaring their preference for Myodil, mainly because of experiences with non-diagnostic water sol- uble myelograms in which the contrast medium had become too dilute. Myodil is now no longer manufactured, and existing stocks have been withdrawn because of the frequency with which it caused chronic adhesive arachnoiditis. ${ }^{34}$

\section{WATER SOLUBLE MYELOGRAPHY}

The advantages of water soluble over oily contrast media were established by use of a substance called Abrodil in Scandinavian countries. This provided superior images of the cauda equina and root sheaths. Other ionic water soluble media such as Conray and Dimer-X enjoyed limited use, but all were too toxic to use other than to show the lower lumbar thecal sac. They are, therefore, irrelevant to the present review. A revolution in myelography occurred when the new nonionic water soluble medium metrizamide (Amipaque) appeared. This was far less neurotoxic than previous ones. It could be used safely around the spinal cord. Inadvertent deposition in the head when running the contrast medium into the cervical region often caused generalised seizures, however; a risk minimised by introducing it by lateral $\mathrm{C} 1-2$ puncture. ${ }^{5}$

By 1983, similar and even less toxic media had been developed and metrizamide was quickly withdrawn. These agents, such as iohexol, do not cause arachnoiditis in the concentrations used in clinical practice, and by 1989 , Skalpe and Sortland were able to state that "epileptic seizures have not been reported following myelography with Omnipaque [iohexol], so it seems that fear of this complication can be virtually disregarded." 6

These media are still not perfect: most patients experience postmyelography headache and about $5 \%$ become confused or develop symptoms such as radicular pain or meningism. ${ }^{7}$ Further agents have been developed, but clinical trials are now difficult to mount because myelography is so little used. Iohexol should be injected by lumbar puncture wherever possible to reduce the risk of injury to the spinal cord or vertebral artery in lateral cervical puncture. ${ }^{8}$ Myelography may cause neurological deterioration due to the spinal puncture, causing injury to the spinal cord or intraspinal bleeding; the disease, resulting in increased cord compression during 
the positioning required for radiography; the procedure, causing raised intraspinal pressure below a subarachnoid block. ${ }^{78}$

\section{$x$ RAY COMPUTED TOMOGRAPHY (CT) OF THE} SPINE

Soon after its introduction for cranial imaging CT was used in the spine. It provided the valuable cross sectional perspective of the spinal canal, formerly very difficult to achieve with conventional radiography. Artefacts caused by bone degrade intraspinal contrast in spinal CT. Intravenous contrast media increase contrast between extradural tissues and CSF, and intrathecal contrast media provide excellent visualisation of the spinal cord and other intradural structures. Patients requiring myelography usually are booked for $\mathrm{CT}$ as well, the findings on the myelogram or the clinical features serving to direct the CT examinations to specific levels. Computed tomography is almost exclusively a cross sectional technique; sagittal and coronal projections require reformatting from stacks of axial slices, and resolution in reformatted planes is not as good as in the plane of data acquisition. Radiation dose can be very considerable, and new guidelines for the use of CT in Britain have been published recently. ${ }^{9}$

\section{MAGNETIC RESONANCE IMAGING (MRI)}

During the period when myelography was being greatly improved, MRI appeared, and within just a few years myelography was pushed almost into obsolescence. With modern high resolution MRI, almost all intradural features demonstrable by myelography can be shown, usually better, by MRI. Myelography is now indicated only when satisfactory MRI cannot be obtained because it is contraindicated (pacemakers, mechanical heart valves, aneurysm clips); it cannot be done (claustrophobia and anaesthesia refused or unsafe, patient cannot fit into the magnet due to obesity, scoliosis, or limb contractures); or it is not available quickly enough, due to lack of on call service or other logistical problems.

Several recent developments have had a special impact on MRI of the spinal cord.

\section{Volumetric (3 D) acquisitions}

The deployment of fast image techniques has permitted three dimensional spatial encoding within a few minutes. This results in multiple contiguous images, no interslice gaps, and section thicknesses down to 1 or $2 \mathrm{~mm}$. The best images of the spinal cord structure are, however, still usually obtained from thicker slices. The best results from volumetric MRI acquisitions are usually obtained on high-field machines.

\section{Fast spin echo (FSE)}

Several phase encoding steps are made at each excitation instead of just one, which greatly reduces acquisition times and permits the use of much larger matrices. This results in twice the resolution in even shorter data acquisition periods. The penalty is slight loss of contrast and increased sensitivity to physi- ological motion, for which it is more difficult to compensate than when single phase encoding steps are used.

\section{Phased array coils}

Spinal imaging requires surface coils, and the phased array configuration enables data to be acquired simultaneously from two or even more surface coils. This permits imaging of the entire spinal cord over one acquisition period and greatly reduces imaging time. Vertebral level counting, sometimes difficult or impossible from single coils, especially in the thoracic region, also becomes easy.

A wide variety of postprocessing options are available on most imagers, or can be purchased separately. These permit multiplanar reformatting in real time, three dimensional surface rendering, colour coding, and many other modifications. The ability to reconstruct in a curved plane is potentially useful in scoliosis, but we have found this of only limited value because most major curvatures are in more than one plane.

\section{Artefacts}

Artefacts are important to consider because they can closely simulate intraspinal disease. Phase dispersion across the image, due to magnetic susceptibility variation and chemical shift effects, reduces sensitivity to biological signal differences and reduces boundary definition. The truncation artefact, generated at boundaries by image processing, is particularly relevant at the CSF-spinal cord interface, and is one possible cause of the band of high or low signal seen in the centre of the cord in midsagittal images. It also causes difficulty in defining the position of the cordCSF boundary where the problem is compounded by susceptibility effects. Phantom studies have shown that both electronic and caliper measurements of the spinal cord, especially in the phase encoding direction, can be artificially reduced by over $2 \mathrm{~mm}$ and may create a spurious impression of spinal cord flattening. ${ }^{10}$

\section{Motion artefacts}

Motion artefacts are generated by cardiosynchronous and oscillatory motion of CSF. This motion has been documented and roughly quantified by MRI. At $\mathrm{C} 2 / 3$, movement is estimated at about $0.65 \mathrm{ml}$ per cardiac cycle, downwards on systole and upwards on diastole. ${ }^{11}$ New data confirm older work indicating that the primary driving force behind intracranial and spinal canal CSF flow is expansion of the brain during vascular systole. The spinal cord and brain stem also descend very slightly on systole and oscillate anteroposteriorly with CSF flow. ${ }^{12}$ In classic studies, Rubin et $a l^{13}$ showed how the oscillatory motions generate linear artefacts parallel to the cord-CSF interface at roughly harmonic intervals across the images in the phase encoding direction, producing signal variation in the spinal cord image that could be easily misinterpreted as intramedullary pathology. ${ }^{13}$ Areas of turbulent CSF flow in 
regions where subarachnoid septa exist, particularly in the thoracic spine, can result in signal variations simulating intradural masses or enlarged vessels. Many strategies have been developed to minimise these problems, but results can be less consistent than is desirable.

The thoracic cord in particular is difficult to image well, especially in cross section, where cardiac motion and the proximity of the aorta add to the motion generated artefacts.

\section{Metallic artefacts}

Metallic artefacts can be particularly destructive of image quality. Many spinal operations utilise metal stabilisation devices, such as plates, rods, screws, and loops, and patients often require postoperative imaging at some stage. Ferromagnetic substances such as stainless steel generate major local artefacts and usually render spinal imaging useless. Tiny fragments from drills and punches, invisible on plain radiographs, may also result in devastating artefacts. ${ }^{14} 15$ Design of implants also can be important such as the avoidance of conductive loops. ${ }^{16}$ The use of titanium for manufacture may have advantages. ${ }^{17} \mathrm{~A}$ wide range of titanium devices has become available only recently, however, and the long term stability and biological effects of these new materials remain under evaluation. ${ }^{18}$

\section{Special techniques}

New methods of brain imaging are usually eventually applied to the spine. Many are being evaluated and only some will be given passing reference here.

Phase contrast imaging utilises bipolar phase encoding gradients; the first brings all spins into phase, the second records reduced signal from moving spins as they dephase relative to stationary spins, due to their motion. This can be used to demonstrate molecular diffusion. One method displays apparent diffusion coefficients across the image and fluid filled cavities appear much brighter than solid areas. ${ }^{19}$ Phase contrast imaging can also be used to demonstrate coherent CSF flow and movement of the neural axis. Phase contrast cine $M R$ produces images that represent velocity as a function of time throughout the cardiac cycle, and by the direction of the phase shift indicate flow direction. ${ }^{20}$ Spatial modulation of magnetism (SPAMM), also referred to as presaturation bolus tracking, is a method whereby regions are tagged by applying a narrow band of saturation before the pulse sequence. This produces a dark stripe across the image that bends in the direction of movement. Multiple presaturation bands can be used to produce a "zebra stripe" pattern, and coupling with a cine loop increases sensitivity in detecting minimal movement. ${ }^{21}$ This has been used extensively to study syringomyelia. Susceptibility contrast weighted dynamic MRI has been used to study blood flow in spinal tumours and arteriovenous malformations..$^{22}$ A susceptibility weighted gradient recalled echo sequence is used to detect the large, transient signal reduction that occurs on the first pass of a bolus dose of intravenous gadolinium through the lesion. Fluid attenuated inversion recovery (FLAIR) sequences are said to offer improved lesion detectability by permitting heavily $\mathrm{T} 2$ weighted acquisition to be accomplished with suppression of all signal from CSF. This removes motion artefact from CSF, which appears paradoxically as signal void on heavily T2 weighted images. Cysts and cystic lesions within the cord also appear, however, as signal void. Most other pathology appears as hyperintensity. At present, imaging with FLAIR is slow and of low resolution, ${ }^{24}$ and like most of the functional imaging methods listed, it has found little general clinical application at present.

\section{SPINAL SONOGRAPHY}

Intraoperative spinal sonography has been used widely in some centres. A minimum of a two or three level laminectomy wound is required, filled with water or saline to act as an acoustic window. ${ }^{25}{ }^{26}$ Although considerable utility has been achieved, ${ }^{25}$ experience has shown that it may not distinguish tumour from cord tissue, may incorrectly identify cysts as solid masses due to unusual echogenicity of some cyst fluids, and cannot reliably distinguish tumoral from non-tumoral cysts. ${ }^{26}$ Surprisingly large transverse excursion of the spinal cord and roots is observed normally, lagging slightly behind the cardiac cycle, and breathing and the Valsalva manoeuvre produce additional abrupt movement. Percutaneous spinal sonography is possible in infants. ${ }^{2728}$ The spinal canal can also be imaged in adults by angling the probe parallel to an intervertebral disc space. Transoesophageal transducers have been used with some success to image the thoracic cord, but clinical utility is virtually non-existent with the availability of MRI. Transuterine sonography has been used to identify dysraphic states in the fetus, ${ }^{29}$ but MRI may also be employed for this purpose.

\section{PLAIN RADIOGRAPHS OF THE SPINE}

Plain films have little part to play in the investigation of spinal cord disease. Inferences can be made about possible sites of spinal cord compression in conditions such as spondylotic myelopathy and trauma, and may suggest the site and type of cord involvement in dysraphic states. The role of plain films in the preliminary investigation of patients with intraspinal lesions was reviewed by Naidich et $a l$ as late as $1986 .^{30}$ The spinal canal is usually enlarged in children with intramedullary tumours. Greatest sensitivity is achieved by graphing the interpediculate distances and comparing them with normal values, but even then the false positive rate is at least $11 \%$. Therefore, plain radiographs have only a very limited screening value even in children.

SPINAL ANGIOGRAPHY

The technique of spinal angiography was developed over 30 years ago by Djindjian and 
Doppman. Today it is indicated only for localisation of the major radiculomedullary arteries before operations on the spine, to study vascular malformations associated with arteriovenous shunts, and before endovascular treatment of a variety of spinal lesions. To demonstrate all the spinal cord arteries, selective injections into the intercostal, lumbar, lumbosacral, vertebral, deep, and ascending cervical arteries is required. Searches for dural fistulae may also require selective injections into branches of the external carotid artery. General anaesthesia is desirable although not essential. Moderate, usually transient, neurological deterioration occurs not uncommonly after extensive spinal angiography, ${ }^{31}$ but paraplegia is rare. ${ }^{32}$ Spinal angiography can be a very laborious undertaking; short cuts have been devised using other imaging modalities and these will be discussed with vascular malformations.

\section{Shape, internal structure, and biomechanics of the spinal cord SIZE AND SHAPE}

Spondylotic flattening of the formalin fixed spinal cord is commonly found at necropsy, and was often considered to be a fixation artefact. Modern imaging has made it abundantly clear that this is not so. Good qualitative agreement is found between the appearance of the spinal cord on cross sectional imaging in living subjects and formalin fixed cords at necropsy, ${ }^{33}{ }^{34}$ but clinical measurement is problematic. The most robust measure of size is cross sectional area. Area measurements could theoretically be accurate within about $\pm 5 \%,{ }^{35}$ but on clinical images it is clear that nothing like this is actually achieved. Electronic window settings profoundly influence all measurements of the cord on computed myelography ${ }^{36}$ and on MRI many other factors are also involved. This is shown by the mean values derived by various workers for their control populations. To give three examples: mean normal cord cross sectional areas at $\mathrm{C} 2$ (where spondylosis is not expected) of $62 \mathrm{~mm}^{2}, 3786.6 \mathrm{~mm}^{2},{ }^{35}$ and $110 \mathrm{~mm}^{238}$ have been reported. Close correlations between area measurements made by computed myelography and MRI were reported by Fukushima et al $(\mathrm{r}=0.901)^{34}$; but the mean values were very different-namely, 0.38 (SD 0.14$) \mathrm{cm}^{2}$ on computed myelography and $0.50(0.16) \mathrm{cm}^{2}$ on MRI. Yu and his colleagues concluded that each department needed to define its own normal range. ${ }^{39}$ It is hardly surprising that no workers have shown a stable relation between cord size, patient age, or body size. Few measurements have been published for the thoracic cord, but we can console ourselves that medical science is not too much the poorer for that.

Two simple measurements of cord shape have been used: circularity $(4 \Pi$ area/circumference ${ }^{2}$ ), ${ }^{35}$ and the compression ratio (ratio of the anteroposterior to transverse diameters)..$^{35} 4041$ Abnormal shapes have also been classified qualitatively in specific types of cord compression, especially cervical spondylosis and its variants, the most comprehensive being by $\mathrm{Yu}$ et al. ${ }^{39}$

INTERNAL STRUCTURE

The internal structure of the spinal cord on MRI seems remarkably similar to an anatomical preparation stained for myelin. More myelinated regions generally yield a lower signal than less myelinated ones. Magnetic resonance imaging has consistently shown variations in texture in histologically uniform regions, such as the anterior horns in the sacral area, Clarke's column, and the dorsal horn complex; the gracile fascicles yield a slightly higher signal than the cuneate. ${ }^{42}{ }^{43}$ In some types of image, the subpial zone has yielded a high signal ${ }^{44}$ and it is uncertain if this represents an MR artefact, or the narrow band of subpial degeneration commonly seen in the cords of aging subjects. It is notable that some authors have forgotten the $\mathrm{T} 1$ shortening that occurs with formalin fixation, making it difficult to obtain images with $\mathrm{T} 1$ weighted contrast.

\section{BIOMECHANICAL PROPERTIES}

Deformation of the cord by transverse compression of up to about $20 \%$ requires minimal force, whereas deformation in excess of $50 \%$ requires forces exceeding capillary perfusion pressure and begins to disrupt both transverse and longitudinal axons. ${ }^{45} 46$ Moreover, spinal cord substance has only a limited capacity for elastic recoil. It has been shown by measurements of cord deformation between flexion and extension on computed myelograms that only about $20 \%$ of a deformation recovers elastically ${ }^{47}$ This has an important implication for interpreting CT and MRI images that are generally performed in positions where the available space for the spinal cord is maximised. Because of its lack of elasticity, it is safe to conclude that if the spinal cord is normal in cross sectional shape, it is not being appreciably compressed in any situation occurring in the patient during normal daily activities; and when deformity is present, it is safe to conclude that the deformity shown reasonably represents the magnitude of intermittent compression. We developed the simple concept of congruous cord deformity, to help distinguish deformation due to intermittent compression from that due to atrophy. When the available subarachnoid space appears capacious on cross sectional images, compression is suggested, nevertheless, if the deformity of the spinal cord is reciprocally congruous with the visible (disc/osteophyte) or expected (reducible subluxation) deformity of the spinal canal; in cord atrophy the deformation is incongruous. ${ }^{48}$

The compressed spinal cord usually increases in size after operative decompression. Fukushima et $a l^{34}$ measured a mean postoperative increase in size of the compressed spinal cord of $13 \%$, varying between $5 \%$ and $20 \%$ in different subgroups of patients, which is of the order one would expect from cord elasticity studies. The cord 
also often changes shape after decompression, becoming less flattened or altered in some other way, because it is very easily deformed by varying conditions.

\section{CORD MOTION}

The cord lies about $2 \mathrm{~mm}$ more posteriorly in the supine than in the prone position, and the cord and vertebral midlines differ by up to 2 $\mathrm{mm}$ in over $40 \%$ of non-scoliotic subjects. ${ }^{49}$

On phase contrast MRI the range of normal cardiosynchronous oscillatory longitudinal movement of the upper cord has been measured to be only $0.4-0.5 \mathrm{~mm} .{ }^{12}$ Initial studies caused excitement because they suggested that assessment of tethering could be made without objective influence of morphological appearances. Reduced oscillatory motion has been seen in the presence of cord tethering, and increased oscillatory motion in Chiari associated syringomyelia. ${ }^{21}$ The actual relevance of any of these findings, however, in the absence of morphological changes, such as a low lying conus medullaris, has, in my opinion, yet to be demonstrated.

\section{Pathological states in cord substance NECROSIS}

Water soluble contrast medium in the subarachnoid space diffuses freely into neural tissue, and $x$ ray attenuation of spinal cord substance measured on CT equilibrates dynamically at about $20 \%$ of that in the subarachnoid space, being removed by the capillary-venous system. ${ }^{50}$ When necrosis occurs, hydrophobic lipid is broken down and the capillary bed destroyed. Contrast medium continues to accumulate in the necrotic region until the CSF concentration falls, and passive diffusion out of the area takes several hours. Necrotic areas thus appear as circumscribed areas of contrast enhancement on computed myelograms, often most conspicuous after six to 12 hours. ${ }^{51}$

On MRI, colliquative necrosis appears as a circumscribed area of signal change. Necrosis, from whatever cause, most often involves mainly the central parts of the spinal cord, in particular the grey matter and ventral parts of the posterior columns. Involvement is usually bilateral, producing either a localised confluent lesion or, more often, bilateral lesions resulting in an appearance likened to snakes' eyes on cross sectional images. ${ }^{52}$

WALLERIAN DEGENERATION

Antegrade degeneration in the long tracts of the spinal cord is seen with pathological states that cause axonal damage. Typically it appears as descending degeneration in the anterior part of the lateral column and ascending degeneration in the posterior columns, which, in diseases of the cervical spine, is often most severe in the fasciculus cuneatus. ${ }^{3341} 4453$

Wallerian degeneration is shown only by MRI. Its appearances have been studied mostly in the brain stem, and only recently in the spinal cord. Four stages are distinguish- able on imaging, which evolve over about 14 weeks. ${ }^{54}$ For up to four weeks, MRI is normal and the chronic stage, characterised by volume loss and increased MR signal, persists indefinitely. Enhancement with intravenous contrast agents does not occur at any stage. In the spinal cord only the chronic stage has been described, ${ }^{44} 55$ but recent experimental studies with magnetisation transfer imaging have demonstrated abnormalities in the earliest stage. ${ }^{56}$

\section{CYSTIC DEGENERATION AND SYRINGOMYELIA} Syringomyelia may result from any pathological process that is liable to cause spinal cord necrosis. It represents an end stage that itself may be progressive and promote further cord damage. The cavities are usually located dorsal to the central canal, with which they may or may not communicate. They may be single or multiple. Only about $15 \%$ extend beyond $\mathrm{C} 2$, and those that do so usually bifurcate around the decussations in the medulla oblongata and come to lie ventral to the floor of the fourth ventricle. Hydromyelia is a cavity consisting mainly of a dilated central canal and communicating with the fourth ventricle. It is closely associated with hydrocephalus, and is collapsed by ventricular shunting. ${ }^{57}$

\section{Chiari I associated syringomyelia}

In the currently most widely accepted hydromechanical theory of causation, this begins as a hydromyelia that subsequently loses communication with the fourth ventricle early in life, resulting in the condition often being referred to as syringohydromyelia. Obstruction of the foramen magnum or the outlets of the fourth ventricle by the descended cerebellar tonsils is central to most hydromechanical theories. In support, phase contrast cine MRI has demonstrated absence of CSF in the cisterna magna due to the abnormal cerebellar tonsils, and restoration of CSF flow after foramen magnum decompression, accompanied by collapse of the syrinx. Also, two groups have recently separately reported a new finding on dynamic MRI: accentuated caudal displacement of the cerebellar tonsils and spinal cord with cardiac systole, which was restored to the normal range, or obliterated altogether, by decompression of the foramen magnum. ${ }^{21}{ }^{58}$ Oldfield et al proposed intermittent piston like obstruction of the foramen magnum by the tonsils. ${ }^{58}$

Although these mechanisms may operate in cases where the cerebellar tonsils do obstruct the foramen magnum, other workers have shown that the foramen magnum is not obstructed by the abnormal cerebellar tonsils in at least $20 \%$ of cases, and the cerebellum would need to move more than 10 times as far as has been recorded to cause intermittent obstruction..$^{59}$ Furthermore, no association exists between the distension or cranial extent of the syrinx and the presence or absence of foramen magnum obstruction, or degree of tonsillar descent ${ }^{59}$; indeed syringomyelia occurs significantly more often with mild rather than with severe tonsillar descent. ${ }^{6061}$ 
Additional complications have arisen with respect to the nature of the Chiari I malformation itself. Firstly, assessment of the level of the cerebellar tonsils on midline sagittal MR images has greatly overestimated the prevalence of tonsillar descent below the foramen magnum. Indeed, a prevalence of between $15 \%$ and $20 \%{ }^{61}$ is still generally accepted despite the previous assessments on myelography and computed cisternography indicating a prevalence of less than $1 \%$. The recent volumetric MRI study of Savy et al, however, has confirmed the second figure to be correct. ${ }^{62}$ Although the apparent prevalence of tonsillar ectopia on sagittal MRI in the study was $20 \%$, it was explained by partial volume averaging and was therefore spurious. Secondly, in over $50 \%$ of cases with true cerebellar ectopia, the medulla oblongata is also elongated. Indeed, a linear relation has been shown between the presence of medullary elongation and severity of the descent of the cerebellar tonsils, ${ }^{63}$ which results in the obex often lying in the cervical canal, not the cranial cavity, and actually lying below the tonsils in about half of such cases. ${ }^{596063}$ These anatomical facts are usually ignored in hydromechanical explanations of syringomyelia and pose appreciable difficulties. Finally, it now seems certain that the Chiari I lesion is an acquired deformation of the rhombencephalon, and not a congenital malformation at all. Serial MRI examinations have clearly shown the development of typical Chiari I deformities postnatally, ${ }^{6465}$ the cause apparently being a lower rate of growth of the basicranium relative to the cerebellum in the first two years of life.

Dynamics and clinical aspects

On air myelography, an important diagnostic observation was whether an enlarged cervical cord collapsed in the head up position. Syringomyelia was collapsing, cord tumours or non-fluctuant cysts were not. Similar findings could be made on water soluble myelography, but the change in cord size was smaller and in the opposite direction, opacified CSF being denser than cyst fluid. ${ }^{51}$ Serial MRI has, however, sometimes revealed large fluctuations in cord size with no intervention whatsoever, and not associated with any change in clinical status. ${ }^{596066}$

There are numerous surgical strategies for collapsing a distended syrinx,${ }^{67}$ the commonest being foramen magnum decompression and syringoperitoneal shunting, either of which will collapse $70 \%-80 \%$. The hypothesis of Williams holds that CSF enters the cord from above, due to intermittent pathological raising of intracranial over intraspinal pressure. ${ }^{68}$ This has been challenged by new intraoperative measurements indicating higher intraspinal pressures, ${ }^{69}$ lending support to alternative hypotheses, which propose that raised intraspinal CSF pressure forces CSF into the cord via the dorsal root entry zone, or Virchow-Robin spaces. Park et al ${ }^{69}$ treated a small series of patients with Chiari associated syringomyelia by lumboperitoneal shunt- ing, and found that this also collapsed the syrinx in about $80 \%$ of cases. This approach has been used in different types of syringomyelia, with similar success ${ }^{70-72}$; the obvious advantage over syringoperitoneal shunting is that it does not interfere with the spinal cord, and it is much less painful and hazardous than foramen magnum decompression.

No correlation can be shown between the degree of distension, or indeed the extent, of a syrinx and severity of clinical features. ${ }^{51} 73.75$ Vaquero et al studied 30 patients clinically and with MRI both preoperatively and postoperatively and showed that collapse of the syrinx was achieved in 29 , but only $46 \%$ improved clinically, and $27 \%$ continued to deteriorate despite MRI showing persistent collapse of the syrinx. ${ }^{75}$ Furthermore, Sherman et al used serial MRI to show that Chiari associated and post-traumatic syringomyelia successfully collapsed by surgical intervention may still continue to propagate through the cord. ${ }^{73}$ Assessment of CSF dynamics by MRI has been just as disappointing in predicting clinical progression or outcome ${ }^{73}$ despite several claims to the contrary based on isolated cases and no follow up data.

\section{Spinal cord compression and injury}

In $25 \%$ of their control population $\mathrm{Yu}$ et al found the spinal cord to be at least moderately compressed by osteophytes at $\mathrm{C} 5 / 6$ or $6 / 7.35$

Some workers have found an apparently linear correlation between numerical evaluation of cord compression (cord cross sectional area or compression ratio) and clinical disability, ${ }^{34404153}$ whereas others have not. ${ }^{377677}$ All studies indicate, however, that when cord compression is sufficient to reduce cord cross sectional area by more than $60 \%$, clinical dysfunction is usually present. Canine models have suggested that lower limb paralysis appears only when gradually applied cord compression exceeds $50 \%$, and that the relation between compression and clinical dysfunction is non-linear, following a catastrophe model rather than a linear one. ${ }^{47}$ More is involved, however, than mere static compression.

In a canine model of chronic spinal cord compression at C5, Al-Sefty et al showed that progressive paraplegia developed in most animals at a mean of seven months after only $30 \%$ compression of the cord. ${ }^{78}$ In a series of patients with chronic malunited fracture of the dens, Crockard et al showed a log linear relation between reduction in cord cross sectional area, as measured on computed myelograms, and time in years since injury. ${ }^{79}$ In another canine model, Anderson showed that a rapidly applied deformation of the cord of only $20 \%-30 \%$ produced much greater damage than slow compression of up to $50 \%$ $60 \%$, and that this consisted mainly of haemorrhagic damage to the grey matter in the first, and mainly white matter change in 
the second. ${ }^{80}$ In chronic compression, although blood flow reduction is maximal in the anterior columns in contact with the compressive agent, paradoxically it is the lateral and the anterior parts of the posterior columns that show pathological change. ${ }^{47}$ In the brain, diffuse axonal injury is the result of shearing forces generated by rotatory acceleration. Similar forces are generated in the spinal cord, where the pia mater is restrained more than the rest of the cord structure by the dentate ligaments and spinal roots, generating shearing forces maximal in the lateral and dorsal columns. ${ }^{33}$ In the brain, very severe rotatory acceleration causes diffuse vascular injury, which is characterised by haemorrhagic damage in the basal ganglia, similar to the grey matter damage seen in the spinal cord. Because the white matter changes generally appear more suggestive of vascular insufficiency than diffuse axonal injury, however, most workers currently believe that progressive cord damage is due to repeated episodes of momentary arrest of the microcirculation. The resulting changes are maximal in the vascular watershed area and tend to lead to cavitation, especially in the ventral parts of the posterior columns; this is readily shown by MRI. ${ }^{78}$

\section{Imaging}

Only MRI consistently shows the changes in the spinal cord that result from compression. They are best shown on T2 weighted images. The distribution is usually characteristic, consisting of diffuse signal change at the site of maximal compression, with variable extension to the central part of the cord, often bilateral, and resulting in an appearance reminiscent of snakes' eyes. 4427881 These changes are shown on $\mathrm{T} 1$ weighted images only when the damage is particularly severe, and consist of low signal; when present they are a sign of poor prognosis. This is not so for signal changes on T2 weighted images, which often disappear completely after operative decompression, but persist when operative outcome is poor. ${ }^{5282}$ The pathological substrate for reversible MRI changes is not known, but it is often assumed to be oedema. The size of the spinal cord at the site of compression is also of prognostic importance. Several studies have shown that when the cord is reduced in size by more than about $50 \%-60 \%$, operative outcome is poor. ${ }^{34} 3776$ This applies only to compression in cervical spondylosis and subluxation. The cord tolerates far greater compression from benign tumours such as meningiomas and schwannomas and functional recovery remains likely after decompression even when the cord is severely compressed.

In a recent computed myelographic study of 56 patients with spondylotic myelopathy who had a poor operative outcome, ${ }^{83}$ an alternative cause for the myelopathy (usually multiple sclerosis) was established in only $14.3 \%$. The spinal cord was reduced in size by $60 \%$ or more at the site of previous compression in only $26.8 \%$, and only $15.6 \%$ had evidence of cord necrosis. In $57 \cdot 1 \%$, operation failed to decompress the spinal canal. Another study by the same workers has put paid to the idea that osteophytes usually regress or disappear after interbody fusion: some osteophytes were as large as they had been up to eight years after the preoperative computed myelogram, and in no case did any measurable regression occur. ${ }^{84}$

Clinicoradiological approach to cord compression in spondylosis and subluxations in the cervical spine

In patients with suspected compressive myelopathy, osteophytes, disc protrusions, or subluxation are irrelevant when the spinal cord is normal or only mildly flattened. Cord deformation of up to about $40 \%$ is also most likely to be irrelevant, unless appropriate signal change is present in the cord on MRI at the site of compression. Usually, however, signal change is present only in severely compressed cords.

Cord deformation of over $50 \%$ is likely to be relevant, but this is also the point at which clinical recovery from decompression is becoming less likely. Therefore, it seems appropriate to consider surgery in asymptomatic or mildly affected children and young adults as a prophylactic measure when cord compression is approaching $50 \%$. In most patients, however, with cervical spondylosis, such operations will be less appropriate because of age and low expectation of deterioration within the relevant time frame. ${ }^{47}$

\section{Acute spinal cord injury}

It is now established in animal models that the extent of signal change shown in the spinal cord on MRI is related to the severity of injury, ${ }^{8586}$ and clinical studies have also shown a general association between the extent of signal change on MRI and functional outcome. ${ }^{87-89}$ Mild or transient loss of function after spinal injury is not usually accompanied by signal change in the cord on MRI ${ }^{87-89}$ In more severe injury, evidence of haematomyelia is present on MRI in only about $50 \%$. Cord swelling is mild and not always present even within seven days of injury, and ongoing cord compression is usually absent. ${ }^{87}$

Progression from an acute injury to localised cystic myelopathy has been followed by serial imaging, most cysts being asymptomatic. ${ }^{82}$ There is good evidence that cysts result from colliquative necrosis, and extension of spindle shaped cores of ectopic necrotic tissue along the bases of the dorsal horns into adjacent uninjured parts of the spinal cord is visible on MRI. ${ }^{84-86} 89$ These necrotic cores are likely to be the basis of the elongated cavities that may occur within a few weeks of injury, ${ }^{82}$ some of which distend and propagate and become associated with a progressive ascending myelopathy. ${ }^{5182}$ Progressive post-traumatic myelopathy can also occur in the absence of cavitation, 5190 and is associated with ascending central necrosis in the spinal cord, manifesting as signal changes on $\mathrm{T} 2$ and $\mathrm{T} 1$ weighted MR 
images $^{90}$ and abnormal accumulation of contrast medium on computed myelography. ${ }^{51}$ Other abnormalities such as adhesions, and occasionally cord compression, are found in some cases; some workers consider these to be the cause of progressive cord damage.

Spinal cord injuries in children differ in some ways from those in adults. ${ }^{91}$ Children may have extensive cord contusion or infarction with minor, remote, or no spinal fracture. Any signal change found on MRI is usually followed by considerable persistent functional loss.

Vertebral artery injury has recently been reported as occurring in nearly $46 \%$ of cases of midcervical fracture dislocation. ${ }^{92}$ It is notable, however, that spinal cord infarction due to vascular injury from subluxation, trauma, or cervical spondylosis and related conditions is exceptionally rare, and its documentation is confined to only two or three case reports over the past 30 years. Extensive and severe adhesive arachnoiditis and superficial siderosis are also described as rare, late complications. ${ }^{93}$

\section{Vascular lesions of the spinal cord} ANATOMY AND PHYSIOLOGY

The blood supply of the spinal cord has recently been reviewed in detail by Lasjaunias and Berenstein. ${ }^{94}$ The anterior spinal artery supplies a centrifugal arterial system and radial arteries from the vascular network on the surface of the cord form a centripetal system. A watershed zone between these systems has been defined consisting of the inner $25 \%$ of the white matter and the outer edge of the grey matter, excluding the posterior $50 \%$ or more of the posterior horns. Regional blood flow in cord white matter of primates has been estimated to be as low as $10 \mathrm{ml} / 100$ $\mathrm{g} / \mathrm{min}$ and in grey matter as $58 \mathrm{ml} / 100 \mathrm{~g} / \mathrm{min}$, which is only about half cerebral blood flow measured by similar techniques. The bases of the dorsal horns seem the most vulnerable regions within the cord to ischaemia or hypoxaemia.

Two main groups of veins drain the spinal cord. The central veins, collecting from both halves and central parts of the cord, and the radial veins from capillary plexuses at the periphery of both grey and white matter. A coronal plexus of veins on the surface of the spinal cord forms a longitudinal network which drains out of the spinal canal along the medullary veins that accompany the spinal roots at varying intervals. These veins are narrowed as they traverse the dura mater, the narrowings perhaps functioning as weak antireflux valves. Although gravity favours inferior venous drainage, in the cervical region cranial venous anastomoses seem of particular importance. High cervical obstruction has been shown to cause venous congestion and stagnant hypoxia in the central parts of the spinal cord in the cervical enlargement.

SPINAL CORD INFARCTION

The MRI appearances have been described in many cases. ${ }^{95-97}$ The commonest change has been diffuse signal increase on $\mathrm{T} 2$ weighted images, most often involving the lower thoracic region. Cord swelling has been mild or absent even in the acute phase. Central haemorrhage has been noted. ${ }^{94}$ In some cases only the ventral part of the cord has been involved, either limited in extent, confined to grey matter, or more diffusely in both grey and white matter. ${ }^{95}$ Diffuse contrast enhancement may be seen after intravenous gadolinium in patients examined $10-21$ days after onset, but not earlier or later. ${ }^{96}$ An association with infarction in adjacent vertebral bodies has been noted. ${ }^{96}$

Venous infarction of the cord has been reported less often, and in two recent cases the MRI abnormality consisted of unilateral signal change. ${ }^{4497}$ One was confirmed by necropsy to be thrombosis of the posterolateral pial vein complex, ${ }^{44}$ and the other was speculated to be due to thrombosis in these veins induced by a YAG laser during removal of an intradural neurinoma at C2. Serial MRI in the second case showed diffuse cord swelling and signal change from $\mathrm{C} 1$ to $\mathrm{C} 3$, which reduced within one month to a circumscribed area of signal change involving nearly all the lateral half of the spinal cord, confined to the site of surgery.

\section{SPINAL VASCULAR MALFORMATIONS}

Dural arteriovenous fistulae

Spinal vascular malformations used to be classified according to the extent of the abnormal intradural vessels, which was a descriptive rather than a functional approach. In the early years of spinal angiography, surgeons believed that most of the vessels were arteries, as did many reputable neuropathologists until very recently. The careful observations of Kendall and Logue revolutionised thinking about these lesions, however, and now form the basis of the modern functional classification. Most spinal arteriovenous malformations are dural arteriovenous fistulae, the enlarged intradural vessels being veins not arteries. The fistula is located in the dura mater close to the nerve roots, usually in the thoracic region in older patients, ${ }^{98} 99$ but can occur in the lumbosacral theca or in the dura mater around the foramen magnum or the posterior cranial fossa. ${ }^{100}$ Slow, aberrant venous drainage is an important feature, and is presumed to be due to thrombosis of radicular veins. Their precise anatomy requires spinal angiography for elucidation. Treatment is often straightforward, by operative or endovascular occlusion of the fistula. Haemodynamic improvement does not always occur, however, because the thrombotic aspect of the disease may remain, with impaired venous drainage of the spinal cord. ${ }^{98}$ Complications of dural fistulae include intramedullary haemorrhage, cord atrophy, and cavitation in the cord, usually above the fistula. ${ }^{98}$

High resolution MRI should detect most clinically relevant arterialised veins, but overdiagnosis is possible. Conventional 
myelography probably remains the most sensitive and specific technique for their detection; however, enlarged or conspicuous intradural veins that drain normally, even if filled by a fistula, are not usually associated with clinical myelopathy. ${ }^{99}$ Virtually all patients with clinical myelopathy have signal changes in the lower part of the spinal cord on MRI, usually surrounded by a small rim of apparently unaltered cord tissue. The signal change often disappears partially or completely when the fistula is successfully closed and symptoms remit, and may reappear if the fistula reopens. There may be patchy enhancement of spinal cord substance after intravenous gadolinium. ${ }^{98} 100$

The site of the fistula can be detected reliably by susceptibility contrast weighted dynamic MRI when the intradural veins are large enough to be shown easily. A series of heavily susceptibility weighted fast images is acquired in the midsagittal plane after an intravenous bolus of gadolinium, and the point at which signal nulling first appears in the intradural veins indicates the level of the fistula. ${ }^{23}$ Spinal angiography can then be directed at this level, greatly speeding up the diagnostic and therapeutic process.

\section{Intramedullary arteriovenous malformations} Intramedullary arteriovenous malformations may be either a nidus, or a direct arteriovenous fistula, located within cord substance or on the pia mater. Fistulae are more common in children. The nidus is often visible on MRI as a focal expansion of the cord closely associated with serpiginous signal voids indicating the draining veins and sometimes enlarged arteries. Successful endovascular treatment may be feasible, even for intramedullary lesions, but multiple sessions may be required, obliteration is often incomplete, and the recurrence rate is high. ${ }^{101}$

\section{Cavernomas and capillary angiomas}

Cavernomas and capillary angiomas are less common in the cord than in the brain. On MRI, they appear usually as localised expansions of the spinal cord, with sharply circumscribed signal change ${ }^{98102}$ that cannot be distinguished from small intramedullary haemorrhages. Intravenous gadolinium enhancement may demonstrate otherwise invisible lesions in rare cases of multiple capillary haemangiomas. ${ }^{103}$

\section{Neoplastic and inflammatory intramedullary processes \\ NEOPLASTIC PROCESSES}

Astrocytomas and ependymomas occur about equally in the spinal cord itself, but ependymomas are much more common in the filum terminale. Extramedullary ependymomas occur occasionally in the extradural part of the filum, involving the sacrum. ${ }^{50}$ Glioblastomas are rare in all ages, as are oligodendrogliomas. Isolated reports are to be found of subependymomas of the cervical cord and gangliogliomas of cervicothoracic cord and filum terminale. Metastases are not uncommon. Primary lymphoma affecting only the spinal cord has now been reported several times. Reports of exceptionally rare neoplasms arising within or directly involving the cord have included melanoma; intramedullary neurofibromas arising from Schwann cells in nerves encasing blood vessels of the cord; intramedullary teratoma, associated with precocious puberty; primitive neuroectodermal tumour; mesenchymal chondrosarcoma without dural attachment, and paraganglioma of the filum terminale.

Finally, there is the relatively common spinal capillary haemangioblastoma, and its well known association with Von HippelLindau disease. Screening of all family members with abdominal CT and spinal MRI with gadolinium enhancement has been recommended by several workers because $40 \%$ of affected patients may be asymptomatic at the time of screening.

On clinical imaging, the hallmark of intramedullary neoplasms is expansion of the spinal cord, usually greater than in inflammatory conditions. Lobulation, or eccentric enlargement is extremely suggestive. Both astrocytomas and especially ependymomas can appear as very well circumscribed signal change on MRI. Sometimes circumscribed lesions appear etched out by a salient low signal pseudocapsule, around the entire circumference or capping the cranial and caudal extremities, consisting of dense gliosis or haemosiderin staining; this is more frequent with ependymomas..$^{50}$ Enhancement after intravenous gadolinium is usual, unlike benign intracranial gliomas, which usually do not enhance. Enhancement is patchy, and does not reliably indicate all neoplastic areas.

Haemangioblastomas and metastases usually have a different appearance. They are well defined, and enhance strongly after intravenous gadolinium. About $50 \%$ of haemangioblastomas are associated with enlarged intrathecal veins, visible on all types of imaging including MRI. Spinal cord oedema is common with metastases and shows up well in white matter with $\mathrm{MRI}^{44}$; it may be difficult to distinguish from cavitation.

Three types of cyst occur in association with intramedullary neoplasms, and about $70 \%$ will have at least one type: intratumoral cysts, the walls containing or consisting of neoplastic tissue; capping cysts, cone shaped cavities extending for one or two spinal segments into uninfiltrated cord cranial and caudal to the tumour; and syringomyelia, undistinguishable from other causes remote from the tumour. ${ }^{50}$ Even on MRI and intraoperative sonography, it can be difficult to distinguish some cystic from solid or necrotic tissue.

\section{INFLAMMATORY PROCESSES}

Until the era of MRI, imaging was usually negative in these conditions, but virtually all inflammatory processes produce changes in cord substance detectable by MRI. Unfortunately, they all look alike and most have been confused with neoplasia. Diagnosis 
usually depends on clinical evolution, laboratory tests, or even cord biopsy, and in many cases the diagnosis remains uncertain.

\section{Multiple sclerosis}

The primary demyelinations, which include acute disseminated encephalomyelitis, present a spectrum of stage dependent changes, ${ }^{50}$ and the stages follow a roughly predictable time course that can be helpful in establishing a diagnosis.

Stage 1: perivenous inflammation and oedemaOn MRI the cord may show mild fusiform enlargement if the lesion is large enough, with poorly defined signal change throughout the involved area, either diffuse or sparing the cord periphery. Clinical dysfunction is at its peak during this phase. Patchy or diffuse enhancement occurs after intravenous gadolinium within the area of signal change, but not coextensive with it. Similarity with cord glioma is particularly close at this stage, which lasts two to eight weeks.

Stage 2: demyelination and glial proliferationOnce MRI cord swelling has subsided, a smaller, more circumscribed area of signal change is evident, and enhancement no longer occurs after intravenous gadolinium. This is how most multiple sclerosis usually presents on MR images. Visualisation is considerably improved by the heavy $\mathrm{T} 2$ weighting provided by spinal FLAIR MRI. ${ }^{104}$ Lesions tend to involve sectors of the cord white matter extending to the periphery of the cord and are best shown on cross sectional T2 weighted images. The posterior columns and the posterior parts of the lateral columns are most commonly involved. The lesions are usually unilateral, or extend across the midline; they do not have the appearance of snakes' eyes. These features should distinguish plaques of demyelination arising in the cervical cord near sites of spondylotic compression, from cord damage due to the compression alone.

Stage 3: atrophy-The spinal cord is small or focally or diffusely flattened. In rare cases, it becomes cavitated.

Nearly all multiple sclerosis lesions eventually progress to stage 3 . Acute disseminated encephalomyelitis lesions usually arrest before this stage, often not progressing beyond stage 1 , and most regress completely. The prognostic significance of brain lesions, which are found at presentation in about $60 \%$ of patients with clinically isolated cord syndromes, has been reviewed recently. ${ }^{105}$

\section{Sarcoidosis}

Involvement of the spinal cord is much less frequent than that of the brain or peripheral nerves in established cases. The appearances on myelography and MRI can be dramatic, although only a few cases have been fully described. ${ }^{106107}$ The cord may show pronounced and extensive fusiform or irregular expansion, with variable signal changes on $\mathrm{T} 1$ and poorly circumscribed high signal on $\mathrm{T} 2$ weighted images. Patchy, non-uniform enhancement usually occurs after intravenous gadolinium and may persist for months. The solid enhancing areas have been shown to consist of astrocytic gliosis in which are embedded typical sarcoid granulomas. One operated case was also found to have extensive cystic change involving almost the entire cord, the cyst containing xanthochromic fluid. Milder forms, indistinguishable from focal multiple sclerosis lesions, have also been documented. ${ }^{50}$ The cord is usually involved along with the brain. Lexa and Grossman described cord involvement in three of 24 established cases of neurosarcoidosis. ${ }^{106}$ The association of changes in periventricular or peripheral white matter in the brain, and leptomeningeal enhancement after intravenous gadolinium, is particularly suggestive of sarcoidosis. Intravenous gadolinium is definitely helpful in identifying meningeal disease and locating additional lesions, which may clinch a difficult diagnosis. Rapid reduction in contrast enhancement, accompanied by clinical improvement, was seen in $90 \%$ of patients in response to steroid treatment. ${ }^{106}$

\section{Spinal tuberculosis}

Spinal tuberculosis has a range of involvement similar to that of sarcoidosis. Meningeal fibrosis with chronic cavitatory myelopathy is more common, especially in countries where tuberculosis has a high prevalence, such as in India, and an MR appearance consisting of multiple superficial enhancing lesions after intravenous gadolinium is probably seen more often. ${ }^{108}$ The diagnosis should be made from the CSF. ${ }^{108}$ Response to antituberculous treatment is variable, as in the brain, and may be preceded by a period of apparent worsening of the appearances.

\section{Intramedullary abscess (pyomyelia)}

Pyomyelia may occur from haematogenous dissemination, but is exceptionally rare. More often there is an underlying abnormality, such as a dermal sinus. ${ }^{109110}$ A peripherally enhancing liquefying mass in a swollen oedematous cord is shown by MRI.

\section{Acute varicella myelopathy}

Herpes zoster can present with neurological disability before the onset of the cutaneous rash, usually consisting of unilateral limb weakness with or without long tract signs. ${ }^{111}$ Magnetic resonance imaging has shown mild enlargement of the spinal cord, with diffuse signal change in the ipsilateral posterolateral portion and coextensive enhancement after intravenous gadolinium. Three or four segments are involved, a little more extensive than the dermatome distribution of the cutaneous rash when it appears. Only partial resolution may follow, with residual signal change in the cord and persistence of some dysfunction. The condition can occur in fit patients as well as those who are immunosuppressed. It is considered to be due to direct involvement of the spinal cord by the virus.

\section{Tropical spastic paraparesis}

Tropical spastic paraparesis is a progressive vacuolar leukomyelopathy showing a strong 
association with human $\mathrm{T}$ cell lymphotrophic virus type $1 \mathrm{HTLV}$ I. The clinical course is relentlessly progressive. The thoracic region is usually involved. Extensive patchy signal change has been shown in the dorsolateral part of the spinal cord, with patchy, sometimes superficial, enhancement after intravenous gadolinium.

\section{Listeria meningoencephalomyelitis}

Listeria monocytogenes produces an encephalomyelitis characterised by multiple microabscesses. Mass lesions can form, simulating malignant tumours. Extensive brain stem and spinal cord involvement has been reported several times. A case presenting as an isolated abscess in the cervical spinal cord was described recently, showing the MRI features of an abscess.

\section{Lyme disease}

Lyme disease may cause an acute transverse myelitis with extensive cord involvement, often associated with involvement of the peripheral nerves. Demaerel et al recently described a case involving just the spinal meninges, and we have encountered a similar case. ${ }^{112}$ In both, only postgadolinium MRI was abnormal, showing pronounced, diffuse enhancement of the pia mater of the brain stem and entire spinal cord. In our case, MRI of the head a few hours after the spinal examination showed that the gadolinium had diffused into the CSF producing a positive contrast cisternogram.

\section{Granulomatous angiitis of the spinal cord}

Granulomatous angiitis is a condition characterised by granulomata involving vascular walls, disseminated through the meninges and neural tissue, which only rarely involves the spinal cord. A case with extensive signal change throughout the spinal cord, showing no enhancement after intravenous gadolinium, has been reported, and another otherwise similar case, which showed extensive mainly superficial enhancement after gadolinium suggestive of metastatic disease ensheathing the cord.

\section{Congenital abnormalities of the spinal cord}

Congenital abnormalities of the spinal cord have been extensively reviewed by Naidich $e t$ $a l$, to whom the interested reader is referred for details. ${ }^{113114}$ Some represent disorders of neurulation of the neural plate and disjunction of the neuroectoderm from the ectoderm; and these include meningomyelocele and lipomas of the spinal cord. In the first, the un-neurulated neural plate (placode) remains part of the integument. In the second, a localised region of the neural tube has failed to neurulate before disjunction occurred and mesenchyme contacting the exposed dorsal surface of the neural plate has differentiated into adipose tissue; disjunction usually was complete and the overlying dura mater is intact, to create an apparently intramedullary intradural lipoma. Spinal roots emerge from the ventral surface of the un-neurulated neural placode in both conditions.

The commonest malformations involve the more caudal part of the neural tube, most of which forms by canalisation of the caudal cell mass that develops in the tail fold of the embryo. When the tail fold disappears, this part of the cord normally undergoes retrogressive differentiation to form the filum terminale. A useful descriptive term for this group of conditions is lipomyelomeningodysplasia to emphasise the elements usually present to some degree in all. The spinal cord or thickened filum extends down, usually to the sacral segments, and blends with a lipoma that extends through a dural defect and neural arch defect of variable size and length to blend with subcutaneous fat. The site of blending with the dura mater and its extent, usually referred to as "tethering", is variable, as is the size and distribution of the lipoma and degree of meningeal ectasia. The spinal cord does not expand into a normal lumbar enlargement and the conus medullaris usually lies at or below L3, its position sometimes being difficult to define.

Another group of conditions seems to be due to much more focal, even punctate, failures of disjunction. A dorsal dermal sinus extends from skin dimple through or between neural arches to the dura, and very occasionally intradurally; about $20 \%$ of spinal dermoids and epidermoids are connected to a dorsal dermal sinus. The neuroectoderm, and ectoderm are normally briefly connected in embryonic life, via the neurenteric canal or adhesion. Persistence of the normal adhesion, or aberrant adhesions at other levels, can result in a connection from foregut to spinal canal, along which neurenteric cysts may form. Intradural spinal neurenteric cysts were well reviewed recently by Brooks et al, ${ }^{115}$ and present a reasonably characteristic appearance on MRI. Persistence of a communication with the skin of the back is a dorsal enteric fistula.

Diastematomyelia is a relatively common anomaly often also considered to be due to aberrant neuroentodermal adhesions. Over a variable number of segments the spinal cord develops as two, usually unequal hemicords, not duplications, although often there are two central canals, median sulci, and anterior spinal arteries. Sometimes this division takes the form only of a deep cleft, but usually the hemicords are entirely separate. In over $50 \%$ of cases, both are enclosed in a common dural tube; the rest are associated with splitting of the dura mater also, and a bony spur arising from malformed thickened laminae then often penetrates between the dural tubes. The spinal cord can be affected at any level, or rarely the filum terminale or medulla oblongata.

Finally, excessive retrogressive differentiation of the tail fold and caudal cell mass can lead to varying degrees of sacral and sacrolumbar agenesis, often referred to as the 
caudal regression syndromes. The spinal cord is abnormally short, the conus lying in the thoracic region at a variable level.

Many of these often dramatic anomalies are asymptomatic, and remain so throughout life. Much recent medical literature is still concerned with their diagnosis, which is now easy, and often seems to exaggerate the importance of timely surgical intervention. This is especially true in the concept of tethering. It has been documented recently that the filum terminale is thicker than $2 \mathrm{~mm}$ and filled with fat in $4 \%$ of normal patients, and that the conus medullaris lies at the level of the lower part of L2 in about $2 \%$ of the normal population. Some workers have indicated that the conus may be tethered, but normal in position, and others that functional MRI or sonography may demonstrate tethering in the absence of any morphological abnormalities. I remain aloof from such opinions at the present time. In cases with progressive disability due to the lesion, structural imaging can be important in demonstrating normal cord tissue giving rise to spinal nerves and in suggesting an operative goal such as debulking of a lipoma or the drainage of a cyst. High resolution MRI has replaced the need for myelography and CT in preoperative assessment of such cases.

1 Shapiro R. Myelography. 3rd ed. Chicago: Year Book Medical Publishers Inc, 1975.

2 Jirout J. Pneumographic examination of the cervical spine. Acta Radiol 1958;50:221-45.

3 Johnson AJ, Burrows E. Thecal deformity after lumbar myelography with iophendylate (Myodil) and meglumine iothalamate (Conray 280). $\mathrm{Br} f{ }^{\prime}$ Radiol 1978;51:196-202.

4 Kendall BE, Stevens JM, Thomas D. Arachnoiditis. Current imaging 1991;2:113-9.

5 Sortland O, Skalpe IO. Cervical myelography by lateral cervical and lumbar injection of metrizamide: a comcervical and lumbar injection of metrizamide:
parison. Acta Radiol 1977;355(suppl):154-63.

parison. Acta Radiol 1977;355(suppl):154-63.
6 Skalpe IO, Sortland O. Myelography. 2nd ed. Oslo: Tano, 1989.

7 Shaw DD, Back-Gansmo T, Dahlstrom K. Iohexol: summary of North American and European clinical trials in adult lumbar, thoracic and cervical myelography, with a new non-issue contrast medium. Invest Radiol 1985;20(suppl):44-50

8 Robertson HJ, Smith PD. Cervical myelography. Survey of modes of practice and major complications. Radiology 1990;174:79-83.

9 National Radiation Protection Board. Protection of the patient in $\mathrm{x}$-ray computed tomography. Chiltern: patient in $\mathrm{x}$.

10 Youser DM, Janick PA, Atlas SW, et al. Pseudo atrophy of the cervical portion of the spinal cord on MR of the cervical portion of the spinal cord on $M R$ images: a manifestation of the truncation

11 Enzmann DR, Pelc AJ. Cerebrospinal fluid-flow measured by phase contrast cine MR. AfNR $A m$ f Neuroradiol 1993;14:1301-7.

12 Mikulis DJ, Wood ML, Zerdoner OAM, Poncelet BP. Oscillatory motion of the normal cervical spinal cord. Radiology 1994;192:117-21.

13 Rubin JB, Enzmann DR. Dyke Award. Harmonic modulation of proton $\mathrm{MR}$ precessional phase by pulsatile motion: origin of spinal CSF flow phenomenon. $A \exists R$ Am $\mathcal{F}$ Roentgenol 1987;148:983-94.

14 Heindel W, Friedmann G, Bunke J, Thomas B, Firsching R, Ernestus RI. Artefacts in MR imaging after surgical intervention. F Comput Assist Tomogr 1986;10:596-9.

15 Yoshino MT, Temeltas OM, Carter LP, et al. Metallic postoperative artefacts on cervical MR. AfNR $A m \mathcal{F}$ Neuroradiol 1993;14:747-9.

16 Clagman DA, Murakami ME, Vines FS. Compatibility of the cervical braces with MR imaging: a study of nine
non-ferrous devices. A尹NR Am 7 Neuroradiol $1990 ; 11$ : non-ferrous

17 Miruis SE, Gecsler F, Joslyn JN, Zrebeet H. Use of titanium wire in cervical spine fixation as a means to reduce artefacts. AfNR Am $\mathcal{F}$ Neuroradiol 1988;9: 1229-31.
18 Williams DF. Editorial; titanium: epitome of biocompatibility or cause for concern. Br $\mathcal{F}$ Bone foint Surg 1994; 76B:348-9.

19 Berry I, Sigal R, Lebas J, Mark AS, Le Bihan D. Magnetic resonance imaging: principles, techniques and imaging protocols. In: Manelfe C, ed. Imaging of the spine and spinal cord. New York: Raven Press, 1992: 157-94.

20 Enzmann DR, Pelc NJ. Normal flow patterns of intracranial and spinal cerebrospinal fluid defined with phasecontrast cine MR imaging. Radiology 1991;178:467-74.

21 Terae S, Miyasaka K, Abe S, et al. Increased pulsatile movement of the hindbrain in syringomyelia associated movement of the hindbrain in syringomyelia associated with Chiari malformation: cine MRI with pres

22 Maeda $M$, Itoh S, Kimura $H$, et al. Vascularity of meningiomas and neuromas: assessment with dynamic susceptibility-contrast MR imaging. $A \mathcal{F} A m \mathcal{F}$ Roentgenol 1994;163:181-6.

23 Thorpe JW, Kendall BE, MacManus D, Miller DH. Dynamic gadolinium enhanced MRI with detection and localisation of spinal arterio-venous malformations. Neuroradiology 1994;36:522-9.

24 White SJ, Haginal JV, Young IR, Bydder GM. Use of fluid attenuated inversion recovery (FLAIR) pulse sequences for imaging the spinal cord. Magn Reson Med 1992;28:153-62.

25 Montalvo BM, Quencer RM. Intraoperative sonography in spinal surgery: state of the art. Neuroradiology 1986;28:551-90.

26 Plainfosse B, Brunon J, Nelson MD, David P, Hurth $M$. Intraoperative ultrasound. In: Manelfe $\mathrm{C}$, ed. Imaging of the spine and spinal cord. New York: Raven Press, 1992:599-620.

27 Rowland Hill CA, Sibson PI, Britton JA, Hall DMB. Ultrasound of the neonatal conus medullaris: normal position and use in identification of occult spinal dysraphism [abstract]. Neuroradiology 1994;36:165.

$28 \mathrm{Di}$ Pietro MA, Venes JL. Real time sonography of the pediatric spinal cord: horizons and limits. Concepts in Pediatric Neurosurgery 1988;8:120-32.

29 Winter RK, McKnight L, Byrne RA, et al. Diastematomyelia: prenatal ultrasonic appearances. Diastematomyelia: prenatal

30 Naidich TP, Doundoulakis SH, Poznanski AK Intraspinal masses: effect of plain spine radiography. Paediatric Neuroscience 1986;12:10-17.

31 Kendall BE. Spinal angiography. In: Du Boulay GH, ed. $A$ textbook of radiological diagnosis. Vol 1 . 5 th ed. The head and CNS. London: Lewis, 1982:563-80.

32 Moseley IF, Tress BM. Extravasation of contrast medium during spinal angiography, a cause of paraplegia. Neuroradiology 1977;13:55-7.

33 Hughes JT. Disorders of the spine and spinal cord. In: Hume Adams J, Duchen IW, eds. Greenfield's neuropathology. London: Edward Arnold, 1992:1083-116.

34 Fukushima T, Takaaki I, Taoka Y, Takata S. Magnetic resonance imaging study of spinal cord plasticity in patients with cerv

$35 \mathrm{Yu}$ YL, Jones SJ. Somatosensory evoked potentials in cervical spondylosis: correlation of median ulnar and posterior tibial nerve responses with radiological findings. Brain 1985;108:273-300

36 Seibert CE, Barnes J, Dreisback JN, et al. Accurate CT measurement of the spinal cord using metrizamide: physical factors. AfNR Am $\mathcal{F}$ Neurobiol 1981;2:75-8.

37 Fijiwara K, Yonenobu K, Ebara S, Yamashita K, Ono K. The prognosis of surgery for cervical compression in myelopathy. F Bone foint Surg 1989;71B:393-8.

38 Sherman JL, Nassaux AB, Citrin CM. Measurements of the normal cervical spinal cord on MR imaging. AfNR Am $\mathcal{F}$ Neurobiol 1990;11:369-72.

$39 \mathrm{Yu}$ YL, Du Boulay GH, Stevens JM, Kendall BE. Computer assisted myelography in cervical spondylotic myelopathy and radiculopathy. Brain 1986;109: 259-78.

40 Fujiwara K, Yonenobu K, Hiroshima K, Ebara S, Yamashita $K$, Ono $K$. Morphometry in cases with compression myelopathy. Spine 1988;13:1212-16.

41 Ogino $\mathrm{H}$, Tada $\mathrm{K}$, Okada $\mathrm{K}$, et al. Canal diameter, antero-posterior compression ratio, and spondylotic myelopathy of the cervical spine. Spine 1983;8:1-15.

42 Beuls E, Gelan J, Vandersteen M, et al. Microanatomy of the excised human spinal cord and the cervicomedullary junction examined with high resolution MR imaging at 9.4 Tesla. AfNR Am fु Neurobiol 1993; 14:699-707.

43 Solsberg MD, Lemaire C, Resch L, Potts DS. High resolution MR imaging of the cadaveric human spinal cord: nom a

44 Ohshio I, Hatayama A, Kaneda K, et al. Correlation between histopathological features and magnetic resonance imaging of spinal cord lesions. Spine 1993;18: nance imas $1140-9$.

45 Brieg A, Turnbull IM, Hasseter O. Effects of mechanical stresses on the cervical cord in cervical spondylosis: a stresses on the cervical cord in cervical spondylosis: a
study on fresh cadaver material. $₹$ Neurosurg 1966;25: 45-66.

46 Stevens JM, O'Driscoll DM, Yu YL, et al. Some dynamic factors in compressive deformity of the cervidynamic factors in compressive deformity of the

47 Stevens JM. The compressed spinal cord. Current medical literature. Medical Imaging 1993;5:3-8. 
48 Stevens JM, Kendall BE, Crockard HA. The spinal cord in rheumatoid arthritis with clinical myelopathy: computed myelographic study. F Neurol Neurosurg Psychiatry 1986;49:140-51.

49 Holsheimer J, Den Boer JA, Struijk JJ, Rozeboom AR. MR assessment of the normal position of the spinal cord in the spinal canal. AfNR Am $\mathcal{F}$ Neuroradiol 1994; 15:951-9.

50 Balériaux D, Parizel P, Bank WD. Intraspinal and intramedullary pathology. In: Menelfe C, ed. Imaging intramedullary pathology. In: Menelfe C, ed. Imaging
of the spine and spinal cord. New York: Raven Press, of the spine and
1992:832-90.

51 Stevens JM, Olney JS, Kendall BE. Post-traumatic cystic and non-cystic myelopathy. Neuroradiology 1985;27: 48-56.

52 Mehali TF, Pezzuti RT, Applebaum BI. Magnetic resonance imaging and cervical spondylotic myelopathy. Neurosurgery 1990;26:217-27.

53 Ono K, Ota H, Tada K, Yamomoto T. Cervical myelopathy secondary to multiple spondylotic protrusions: a clinicopathological study. Spine 1977;2:109-25.

54 Kuhn MJ, Mikulis J, Ayoub DM, et al. Wallerian degeneration after cerebral infarction: evaluation with eration after cerebral infarction: evaluation

55 Terae S, Taneichi H, Aburni K. MRI of Wallerian degeneration of the injured spinal cord. $\mathcal{F}$ Comput Assist degeneration of the injur.

56 Lexa FJ, Grossman RI, Rosenquist AC. MR of Wallerian degeneration in the feline visual system: characterisation by magnetisation transfer rate with histopathological correlation. AfNR Am $\mathcal{f}$ Neuroradiol 1994;15 201-12

57 Naidich TP, Zimmerman RA, McLone DG, et al. Congenital malformations of the spine and spinal cord. In: Manelfe C, ed. Imaging of the spine and spinal cord. New York: Raven Press, 1992:621-704.

58 Oldfield EH, Muraszko K, Shawker TH, Patronas NJ. Pathophysiology of syringomyelia associated with Chiari I malformation of the cerebellar tonsils: implications for diagnosis and treatment. $\mathcal{F}$ Neurosurg 1994; tions for
$\mathbf{8 0}: 3-15$.

59 Clifton A, Stevens JM, Kendall BE. Idiopathic and Chiari associated syringomyelia in adults: observation on the cerebrospinal fluid pathways at the foramen magnum. Neuroradiology 1991;33(suppl):167-9.

60 Stevens JM, Serva W, Kendall BE, et al. Chiari malformation in adults: relation of morphological aspects to
clinical features and operative outcome. $\mathcal{f}$ Neurol Neurosurg Psychiatry 1993;56:1072-7.

61 Barkovich AJ, Wippold FJ, Sherman JJL, Citrin CM. Significance of cerebellar tonsillar position on MRI AfNR Am $\mathcal{F}$ Neuroradiol 1986;7:795-9.

62 Savy L, Stevens JM, Taylor DJ. Apparent cerebellar ectopia: a reappraisal using volumetric MRI Neuroradiology 1994;6:360-3.

63 Stevens JM, Clifton A, Kendall BE. Relationship between cerebellar tonsillar descent, medullary elongabetween cerebellar tonsillar descent, medullary elongation and the basi cranium in hindbrain deformities

64 Payner TD, Prenger E, Berger TS, Crone KR. Acquired Chiari malformations: incidence, diagnosis and management. Neurosurgery 1994;34:429-34.

65 Huang PP, Constantine S. "Acquired" Chiari I malformations. F Neurosurg 1994;80:1099-102.

66 Birbamer G, Buchberger W, Felber S, et al. Spontaneous collapse of post-traumatic syringomyelia: serial mag-
netic resonance imaging. Eur Neurol 1993;33:378-81.

67 Milhorat TH, Johnson WD, Miller JI, et al. Surgical treatment of syringomyelia based on magnetic resotreatment of syringomyelia based on magnetic reso-

68 Williams B. Pathogenesis of syringomyelia. Lancet 1972; i: $142-3$.

69 Park TS, Cail WS, Broneldus WC, et al. Lumbo-peritoneal shunt combined with myelotomy for treatmen of syringo-hydromyelia. $\mathcal{f}$ Neurosurg 1989;70:721-7.

70 Vissilouthis J, Panandreon A, Anagnostasas S. Thecoperitoneal shunt for post-traumatic syringomyelia. $\mathcal{F}$ Neurol Neurosurg Psychiatry 1994;57:755-6. 71 Vissilouthis J, Panadreon A, Anagnostasas S. three cases. Neurosurgery 1993;33:324-8.

72 Vengsarkar VS, Panchal VS, Tripathis PB, et al. Percutaneous theco-peritoneal shunt for syringomyelia. Report of three cases. $\mathcal{F}$ Neurosurg 1991;74:827-31.

73 Sherman JL, Barkovich AJ, Citrin CM. The MR appearances syringomyelia: new observations. AfNR $A m$ f ances syringomyelia: new
Neuroradiol 1986;7:985-95.

74 Grant R, Hadley DM, MacPherson P, et al. Syringomyelia - cyst measurement by magneticresonance imaging and comparison with symptoms, signs, and disability. $f$ Neurol Neurosurg Psychiatry 1987:50:1008-14.

75 Vaquero J, Martinez R, Arias A. Syringomyelia-Chiari complex. Magnetic resonance imaging and clinical evaluation of surgical treatment. $\mathcal{F}$ Neurosurg 1990;73: $14-68$.

76 Hunter JV, Stevens JM, Kendall BE, et al. Radiological assessment of transoral surgery in rheumatoid arthritis using dynamic CT myelography. Neuroradiology 1991; 33(suppl):413-5.

77 Yu YL, Stevens JM, Kendall BE, de Boulay GH. Cord shape and measurement in cervical spondylotic myelopathy and radiculopathy. AfNR Am $\mathcal{F}$ Neuroradiol 1983;4:839-42.
78 Al-Mefty O, Harkey HL, Marawi I, et al. Experimental compressive cervical myelopathy. $\mathcal{F}$ Neurosurg 1993;79: 550-61.

79 Crockard HA, Heileman AE, Stevens JM. Progressive myelopathy secondary to odontoid fractures: clinical radiological and surgical features. $f$ Neurosurg 1993; 78:579-86.

80 Anderson TE. Spinal cord contusion injury. Experimental dislocation of haemorrhagic necrosis and subacute long axonal conduction loss. $f$ Neurosurg subacute long
1985;62:115-9.

81 Schonman-Claeys E, Frija S, Caenol CA, et al. MR imaging of acute spinal cord injury: results of an experimental study in dogs. AfNR Am f Neuroradiol 1990; 11:459-65.

82 Yamashita Y, Takahaiki M, Matsumoto Y, et al. Chronic injuries of the spinal cord: assessment with MR imaging. Radiology 1990;175:849-54.

83 Clifton AG, Stevens JM, Whitear PW, Kendall BE. Identifiable causes for poor outcome in surgery for cervical spondylosis. Post-operative computed myelography and MR imaging. Neuroradiology 1990;32: $450-5$.

84 Stevens JM, Clifton AG, Whitear P. Appearances of posterior osteophytes after sound anterior interbody fusion in the cervical spine: a high definition computed myelographic study. Neuroradiology 1993;35:227-8.

85 Hackney DB, Ford JC, Markowitz RS, et al. Experimental spinal cord injury: MR correlations to intensity of injury. $\mathcal{F}$ Comput Assist Tomogr 1994;18: 357-62.

86 Fujii H, Yore K, Sakou I. Magnetic resonance imaging study of experimental acute spinal cord injury. Spine 1993;18:2030-4.

87 Kulkarni MR, McArdle CB, Kapanick D, et al. Acute spinal cord imaging: MR imaging at $1.5 \mathrm{~T}$. Radiology 1987;164:837-43.

88 Silberstein $M$, Hennessy $O$. Implications of focal spinal cord lesions following trauma-evaluation with magnetic resonance imaging. Paraplegia 1993;31:160-7.

89 Beers GJ, Rague GH, Wagner SG, et al. Magnetic resonance imaging of spinal trauma. F Comput Axial Tomogr nance imaging of

90 Falcone S, Quencer RM, Green BA, et al. Progressive post-traumatic myelomalacic myelopathy: imaging and clinical features. AfNR Am $\mathcal{F}$ Neuroradiol 1994; 15:747-54.

91 Davies PC, Reisner A, Hudgins PA, et al. Spinal injuries in children: role of MR. AfNR Am $\mathcal{F}$ Neuroradiol 1993; 14:607-17.

92 Willis BK, Greiner F, Orrison WW, Benzel EC. The incidence of vertebral artery injury after mid-cervical fracture or subluxation. Neurosurgery 1994;34:435-42.

93 Bonito V, Agostinis C, Ferraresi S, Defanti CA. Superficial siderosis of the central nervous system after brachial plexus injury with pseudo meningoceles. brachial plexus injury with
$\mathcal{J}$ Neurosurg 1994;80:931-4.

94 Lasjaunias P, Berenstein A. Surgical neuroangiography. Vol 3. Functional vascular anatomy of brain, spinal cord and 3pine. New York: Springer Verlag, 1990:15-87.

95 Mawad ME, Rivera V, Crawford S, et al. Spinal cord ischaemia after resection of thoraco-abdominal aortic aneurysms: MR findings in 24 patients. AfNR $\mathrm{Am} \mathcal{J}$ Neuroradiol 1990;11:987-91.

96 Yuh WT, Marsh CY, Wang AK, et al. MR Imaging of spinal cord and vertebral body infarction. AfNR Am $\mathcal{F}$ Neuroradiol 1992;13:145-54.

97 Henderson FC, Crockard HA, Stevens JM. Spinal cord oedema due to venous stasis. Neuroradiology 1993; 35:312-5.

98 Rodesch G, Berenstein A, Lasjaunias P. Vasculature and vascular lesions of the spinal cord. In: Manelfe $C$, ed. Imaging of the spine and spinal cord. New York: Raven Imaging of the spine

99 Willinsky $R$, Lasjaunias $P$, Terbrugge $K$, Hurth $M$. Spinal angiography in the investigation of spinal arteriovenous fistula. A protocol with application to the venous phase. Neuroradiology 1990;32:114-6.

100 Gaensler EHL, Jackson DE, Halbach VV. Arteriovenous fistulas of the cervico-medullary junctions as a cause of myelopathy: radiological findings in two cases. AFNR Am F Neuroradiol 1990;11:518-22.

101 Biondi A, Merland JJ, Reizine D, et al. Embolization with particles in thoracic intramedullary arterio-venous malformations: Long term angiographic and clinical results. Radiology 1990;177:651-8.

102 Barnwell SL, Dowd CF, Davis RL, et al. Cryptic vascular malformations of the spinal cord: diagnosis by magnetic resonance imaging and outcome of surgery. netic resonance imaging

103 Hida K, Tada M, Chandler WF, et al. Intramedullary disseminated capillary haemangioma with spinal cord

104 Thomas DJ, Pennock JM, Hajnel, et al. Magnetic resonance imaging of the spinal cord in multiple sclerosis by fluid attenuated invasion recovery (FLAIR). Lancet 1993;314:593-4.

105 Morrissey SP, Miller DH, Kendall BE, et al. The significance of brain magnetic resonance imaging abnormalities at presentation with clinically isolated syndromes suggestive of MS: a 5 year follow up study. Brain 1993;116:135-46.

106 Lexa FJ, Grossman RI. MR of sarcoidosis in the head and spine: spectrum of manifestations and radiographic 
response to steroid therapy. AfNR Am $\mathcal{f}$ Neuroradio 1994;15:973-82.

107 Stevens JM. Infections of the central nervous system. In Butler $\mathbf{P}$, ed. Imaging of the nervous system. London Springer-Verlag, 1990:107-30.

108 Junger SS, Stern BJ, Levine SR, et al. Intramedullary sarcoidosis - clinical and magnetic imaging characteristics. Neurology 1993;43:333-7.

109 Rogg JM, Benzil DL, Haas RL, Knucky NW. Intramedullary abscess, an unusual manifestation of a dermal sinus. AfNR Am ₹ Neuroradiol 1993;14:1393-5.

110 Hardwidge C, Palsingh J, Williams B. Pyomyelia: an intramedullary abscess complicating lumbar lipoma intramedullary abscess complicating lumbar
with spina bifida. $B r \exists$ Neurosurg 1993;7:419-22.

111 Esposito MB, Arrington JA, Murtaugh FR, et al. MR of the spinal cord on a patient with Herpes zoster. $A \mathcal{F N R}$ Am $\mathcal{F}$ Neuroradiol 1993;14:203-4.
112 Demaeral R, Wilms G, Van Lierde S, et al. Lyme disease in childhood presenting as primary leptomeningeal enhancement without parenchymal findings on MR. AfNR Am $\mathcal{F}$ Neuroradiol 1994;15:302-4.

113 Naidich TP, Zimmerman RA, McLone DG, et al. Congenital anomalies of the spine and spinal cord. In Scott Atlas, ed. Magnetic resonance imaging of the brain and spine. New York: Raven Press, 1991:865-920.

114 Naidich TP, McLone DG, Harwood-Nash D. Spinal dysraphism. In: Newton PH, Potts DG, eds. dysraphism. In. Newton PH, Potts DG, eds. Modern neuroradiology. Vol 1. Computed tomography of the spine and spinal cord. San Anselmo, CA: Clavadel Press,

115 Brooks BS, Duval ER, El Gammal T, et al. Neuroimaging features of neurenteric cysts: analysis of nine cases and review of the literature. $A \mathcal{F N R} A \mathrm{~m}^{\prime}$ Neuroradiol 1993; 14:735-46.

\section{NEUROLOGY IN LITERATURE}

\section{Disorders of higher cortical function}

I have written before of Darius Clayhanger's dressing apraxia. ${ }^{1}$ The account was based on Bennett's father. The underlying pathological process is not clear from Bennett's journals although I have suggested that it is possible that the condition was a rare form of Pick's disease. Bennett returns briefly to the problem in These twain. Most of the other extracts are concerned with memory failure either as part of senescence, or as part of a specific dementing illness. Mr Candy, in The moonstone, develops a memory disorder after a flu-like illness, conceivably, therefore, the sequela of an encephalitic illness. Proust's musings, expressed in his typically convoluted sentences, belong more in the realm of philosophy than neurology. It has been suggested elsewhere that Mrs Gradgrind's curious inability to relate her pain to her own body is part of a parietal disorder, although there is nothing in the novel to support that interpretation.

Fonathan Swift, 1726, Gulliver's travels

At ninety they lose their teeth and hair; they have at that age no distinction of taste, but eat and drink whatever they can get, without relish or appetite. The diseases they were subject to, still continue without encreasing or diminishing. In talking, they forget the common appellation of things, and the names of persons, even of those who are their nearest friends and relations. For the same reason, they can never amuse themselves with reading, because their memory will not serve to carry them from the beginning of a sentence to the end; and by this defect, they are deprived of the only entertainment whereof they might otherwise be capable.

Charles Dickens, 1854, Hard times

"I think there's a pain somewhere in the room," said Mrs Gradgrind, "but I couldn't positively say that I have got it."

George Eliot, 1863, Romola

He was not mad; for he carried within him the piteous stamp of sanity, the clear consciousness of shattered faculties; he measured his own feebleness. . . .

Would any believe that he had ever had a mind filled with rare knowledge, busy with close thoughts, ready with various speech? It had all slipped away from him-that laboriously gathered store . . . but he found, to his acute distress, that of the new details he learned he could only retain a few, and those only by continual repetition; and he began to be afraid of listening to any new discourse, lest it should obliterate what he was already striving to remember...

Old men's eyes are like old men's memories; they are strongest for things a long way off.
Wilkie Collins, 1868, The moonstone

Here, he got on glibly enough. Trumpery little scandals and quarrels in the town, some of them as much as a month old, appeared to recur to his memory readily. $\mathrm{He}$ chattered on, with something of the smooth gossiping fluency of former times. But there were moments, even in the full flow of his talkativeness, when he suddenly hesitated-looked at me for a moment with the vacant inquiry once more in his eyes - controlled himself - and went on again.

\section{Fyodor Dostoyevsky, 1869, The idiot}

The General talked for ten minutes, heatedly and rapidly, as though too engrossed for time to express the thoughts that crowded in his head; towards the end, tears glistened in his eyes. And yet it was only sentences without beginning or end, unexpected words and unexpected ideas, rapidly and unexpectedly bursting forth and stumbling over one another.

\section{Arnold Bennett, 1910, Clayhanger}

For many months now he had helped Darius to dress, when he came up from the shop for breakfast, and to undress in the evening. It was not that his father lacked the strength, but he would somehow lose himself in the maze of his garments, and apparently he could never remember the proper order of doffing or donning them. Sometimes he would ask, "am I dressing or undressing?" And he would be capable of so involving himself in a shirt, if Edwin were not there to direct, that much patience was needed for his extrication. His misapprehensions and mistakes frequently reached the grotesque. As habit threw them more and more intimately together, the trusting dependence of Darius on Edwin increased. At morning and evening the expression of that intensely mournful visage seemed to be saying as its gaze met Edwin's, "here is the one clear-sighted, powerful being who can guide me through this complex and frightful problem of my clothes." A suit, for Darius, had become as intricate as a quadratic equation.

\section{Arnold Bennett, 1916, These twain}

. . . but it had witnessed hundreds of monotonous tragic meals at which the progress of his father's mental malady and the approach of his death could be measured by the old man's increasing disability to distinguish between his knife and his fork.

Marcel Proust, 1919, Remembrance of things past: within a budding grove

For our memory, relatively to the complexity of the impressions which it has to face while we are listening, is infinitesimal, as brief as the memory of a man who in his sleep thinks of a thousand things and at once forgets them, or as that of a man in his second childhood who cannot recall a minute afterwards what one has first said to him. 